\title{
Effect of xantham gum, steviosides, clove, and cinnamon essential oils on the sensory and microbiological quality of a low sugar tomato jam
}

\author{
María F Gliemmo ${ }^{1,2}$, María A Montagnani ${ }^{3}$, Laura \\ I Schelegueda ${ }^{1,2}$, Malena M González ${ }^{1}$ and Carmen A Campos ${ }^{1,2}$
}

\begin{abstract}
The partial or total decrease of sugar content in the formulation of jams affects their physical, chemical and microbiological stability. In order to minimize these technological problems, we studied the effect of xanthan gum (XG), steviosides, cinnamon (CO), and clove (CLO) essential oils on the sensory and microbiological quality of a low sugar tomato jam. Levels of $0.250 \mathrm{~g} / 100 \mathrm{~g}$ steviosides and $0.450 \mathrm{~g} / 100 \mathrm{~g} \mathrm{XG}$ showed maximum score of overall acceptability of jam. The combination of essential oils produced synergistic and additive effects in vitro on growth of $Z$. bailii and $Z$. rouxii, respectively. However, in the jam, CO was more effective and CLO did not modify the CO action. Cell surface was one of the sites of action of $C O$ since a decrease in yeast cell surface hydrophobicity was observed. From the microbiological and sensory points of view, $0.0060 \mathrm{~g} /$ $100 \mathrm{~g}$ CO showed the maximum score of jam overall acceptability and did not cause yeast inactivation but it could be useful as an additional stress factor against yeast post - process contamination. The adequate levels of XG, steviosides, and CO can improve the quality of a low sugar jam formulation.
\end{abstract}

\section{Keywords}

Steviosides, xanthan gum, cinnamon oil, low sugar jam, spoilage yeasts

Date received: 17 August 2014; accepted: 21 January 2015

\section{INTRODUCTION}

Over the past decades, obesity has reached epidemic rates worldwide. Obese people are at increased risk of diabetes, cardiovascular disease, and hypertension, among others chronic diseases (World Health Organization, 2014). These facts led to the development of foods with low sugar content, such as jams. The partial or total decrease of sugar content in jams affects their physical, chemical, and microbiological stability. The decrease in sweetness, body, and mouthfeel, as well as changes in the appearance and the increase in water activity $\left(\mathrm{a}_{\mathrm{w}}\right)$ of low sugar jams are the technological problems to be solved (Basu and Shivrave, 2010). Reducing the sweet taste may be offset by the addition

Food Science and Technology International 0(0) 1-10

(C) The Author(s) 2015 Reprints and permissions:

sagepub.co.uk/journalsPermissions.nav

DOI: $10.1177 / 1082013215574400$

fst.sagepub.com

๑SAGE of sweeteners, while the presence of thickeners may improve mouthfeel and appearance. Moreover, the increase in $\mathrm{a}_{\mathrm{w}}$ may affect the microbiological stability of foods, making the addition of preservatives necessary.

The consumer demand for a reduction of synthetic additives' intake promotes the search for natural additives that replace all or part of them in food

\footnotetext{
${ }^{1}$ Departamento de Industrias, Facultad de Ciencias Exactas y Naturales, Universidad de Buenos Aires, Int. Güiraldes 2160, Ciudad Universitaria, Buenos Aires, Argentina

${ }^{2}$ Members of Consejo Nacional de Investigaciones, Científicas y Técnicas de la República Argentina

${ }^{3}$ Instituto Nacional de Tecnología Agropecuaria, Estación Experimental, Área Metropolitana Buenos Aires, Capital Federal, Argentina
}

Corresponding author:

María F Gliemmo, Departamento de Industrias, Facultad de Ciencias Exactas y Naturales, Universidad de Buenos Aires. Ciudad Universitaria. Int. Güiraldes 2160. CP 1428 Buenos Aires, Argentina.

Email: mfg@di.fcen.uba.ar 
formulations. In this sense, stevia is gaining interest. This sweetener is extracted from the leaves of Stevia rebaudiana (Bertoni), an herb native to Paraguay. The extract is 300 times sweeter than sucrose and also has a hypoglycemic response making it attractive for diabetic people (Chatsudthipong and Muanprasat, 2009). Its use as a food additive has been approved in a number of countries, including Argentina, USA, Brazil, Paraguay, China and the European Union. Since then, it is one of the most used sweeteners to replace sugar in food formulations over the world (Prakash et al., 2008; Scott-Thomas, 2013).

The reduction of sugar level necessitates the addition of thickeners that improve mouthfeel and appearance. For this purpose, xanthan gum $(\mathrm{XG})$ is frecuently used. It is a heteropolysaccharide produced by Xanthomonas campestris. It is non-toxic and has been approved by the Food and Drug Administration (FDA) for use as a food additive without concentration limits. It is widely used in the formulation of sauces, syrups, salad dressings and jams (García-Ochoa et al., 2000; Sikora et al., 2008).

Some of the hurdles applied to preserve low sugar foods are: the decrease in $\mathrm{pH}$ and $\mathrm{a}_{\mathrm{w}}$, thermal treatment and the use of preservatives. These hurdles prevent the growth of pathogens but are overcome by spoilage yeasts, such as Zygosaccharomyces bailii and Zygosaccharomyces rouxii (Stiles et al., 2002). These yeasts are osmophilic, acid tolerant, and preservative resistant (Gliemmo et al., 2006). They are able to grow under anaerobic atmosphere, exhibit minimum nutritional needs, and are resistant to pasteurization and to cleaning agents. As a consequence, their growth leads to significant economic losses (Deak, 2008; Loureiro and Querol, 1999; Praphailong and Fleet, 1997). Therefore, the control of yeast growth in acidic products is of interest.

The use of essential oils as natural preservatives in foods has reemerged. Some essential oils have been used in medical treatments.

The antimicrobial action of essential oils is attributed to the penetration of lipophilic components through the membrane to the site of action within the cell ( $\mathrm{LV}$ et al., 2011). Cinnamon (CO) and clove oils (CLO) inhibit the growth of molds, yeasts and bacteria in vitro and in vivo (Conner and Beuchat, 1984; Goñi et al., 2009; Matan et al., 2006; Prabuseenivasan et al., 2006). However, the information about the use of these oils against yeasts growth is scarcely reported.

The replacement of sucrose by thickeners, sweeteners and preservatives in low sugar jams needs the sensory quality assessment to minimize the differences with regular jams and to avoid an unacceptable sensory impact. The addition of low methoxyl pectin and the mixture aspartame/acesulfame-K to a low calorie fruit jelly did not affect the overall acceptability (Acosta et al., 2008). Carrageenan addition improved the mouthfeel of a low-calorie Christophene jam (Gajar and Badrie, 2001).

The presence of essential oils may produce undesirable flavors in foods. Few studies measure the inhibitory concentrations of essential oils and analyze their effect on the sensory properties of food. A level of $0.25 \mu \mathrm{l} / \mathrm{ml}$ lemon essential oil extended the shelf life of clear apple juice and exerted a positive influence on its taste (Tserennadmid et al., 2011). Carrot slices treated with oregano, marjoram, basil and lemon balm solutions were sensory acceptable but only oregano and marjoram treatments had positive scores of overall acceptability for lettuce (Gutierrez et al., 2008). To reduce the sensory impact of the essential oil, the use of $1 \% \mathrm{v} / \mathrm{w}$ CLO in combination with low temperature has been proposed to preserve chicken frankfurters (Mytle et al., 2006).

In order to minimize the technological problems arising from the formulation of low sugar jams, we studied the effect of natural additives on sensory properties and microbiological stability of a low sugar tomato jam. For that purpose, on a first stage, the effect of XG and steviosides was evaluated on overall acceptability of the jam by the use of a full factorial design. On a second stage, antimicrobial activity of $\mathrm{CO}$ and CLO was assayed against spoilage yeasts in vitro and in the jam containing the optimal sensory levels of XG and steviosides. Finally, the sensory and microbiological quality of the jam containing different levels of $\mathrm{CO}$ was studied.

\section{MATERIALS AND METHODS}

\section{Materials}

Glucose, citric acid and calcium chloride were from Merck Química (Argentina, Argentina); vanilla, CO (Ceylon Type, natural identical), CLO (Syzygium aromaticum), and 2,3,5-triphenyltetrazolium chloride were from Sigma-Aldrich (USA), and glycerol was from Sintorgan S.A. (Argentina). All of them were of reagent grade. Steviosides $(90 \mathrm{~g} / 100 \mathrm{~g}$ of a mixture of steviosides and $10 \mathrm{~g} / 100 \mathrm{~g}$ maltodextrin) was from Inmobal Nutrer (Argentina), xylitol was from Gelfix (Argentina), and xanthan gum and low methoxyl pectin were from Cargill (Argentina). All of them were of food grade. All culture media used for microbiological evaluations (SB, Sabouraud broth; SA, Sabouraud agar; bacteriological agar; PCA, plate count agar; MRS, de Man, Rogosa and Sharpe agar; and VRBL, violet red bile lactose agar) were from Biokar (Biokar Diagnostics, Beauvais, France).

\section{Processing of jam}

Fresh tomatoes (Lycopersicum esculentum), purchased from the local market (Buenos Aires, Argentina), were 
washed, peeled off, de-seeded, and cut into cubes. Five jams were prepared according to a $2^{2}$ full factorial design with two variables (XG and steviosides) at two levels and a central point (Table 1) in three blocks. The remaining composition is shown in Table 2. The jams were elaborated following the general processing steps showed in Figure 1. The sugar content was reduced by the addition of xylitol and glucose, reaching $30^{\circ}$ Brix at the end of cooking. This value includes $10 \mathrm{~g} / 100 \mathrm{~g}$ assimilable carbohydrates and $20 \mathrm{~g} / 100 \mathrm{~g}$ xylitol, which have caloric values of 4.0 and $2.4 \mathrm{kcal} / \mathrm{g}$, respectively.

The total soluble solids content were recorded during the process with a refractometer (Westover, China). The $\mathrm{pH}$ was adjusted to 3.50 by addition of citric acid. It was determined with a $\mathrm{pH}$ meter Solution Analyzer 5800-05 (Cole-Parmer, Chicago, IL, USA) provided with a glass electrode. The pasteurization was performed in an electric sterilizer (Tuttnauer 3150, Israel).

\section{Effect of xanthan gum and steviosides on overall acceptability of a tomato jam}

A group of 100 consumers ( 35 males and 65 females) of low sugar jams evaluated the overall acceptability of jams at three days after elaboration using a balanced verbal 9-point hedonic scales $(1=$ dislike very much; $9=$ like very much) (Meilgaard et al., 1987). Assessors received the samples at room temperature, served in coded containers $(10 \mathrm{~g})$, in randomized order and in three replicated sessions as it was recommended by Meilgaard et al. (1987).

\section{Yeasts strains and inoculum preparation}

Zygosaccharomyces bailii NRRL 7256 and Zygosaccharomyces rouxii ATCC 28.253 inocula were prepared separately. The strains were stored at $-20.0 \pm 0.5^{\circ} \mathrm{C}$ in $\mathrm{SB}$ plus $10.0 \mathrm{~g} / 100 \mathrm{~g}$ glycerol. Before their use, they were grown twice in SB at $25.0 \pm 0.5^{\circ} \mathrm{C}$ during $24 \mathrm{~h}$. After that, each inoculum was diluted in peptone water $(1.5 \mathrm{~g} / 100 \mathrm{~g})$ to reach 0.5 McFarland units, corresponding to a population of approximately $10^{6} \mathrm{CFU} / \mathrm{ml}$.

\section{Screening for antimicrobial activity of essential oils}

The agar disk diffusion method was used ( $\mathrm{Lv}$ et al., 2011). Plates containing solidified SA were seeded on a surface with $1 \mathrm{ml}$ of the diluted inocula of yeasts. Then, sterile blank filter disks (6 mm diameter, Oxoid) were applied on the surface and seeded with $10 \mu 1$ of each essential oil. After $24 \mathrm{~h}$ of incubation at
Table 1. Levels $(\mathrm{g} / 100 \mathrm{~g})$ of xanthan gum (XG) and steviosides in jams in the factorial design.

\begin{tabular}{ll}
\hline $\begin{array}{l}\text { Concentration } \\
\text { XG }\end{array}$ & Steviosides \\
\hline 0.450 & 0.000 \\
0.225 & 0.125 \\
0.000 & 0.000 \\
0.000 & 0.250 \\
0.450 & 0.250 \\
\hline
\end{tabular}

Table 2. Jam composition ( $\mathrm{g} / 100 \mathrm{~g})$.

\begin{tabular}{lc}
\hline Ingredient $^{\mathrm{a}}$ & Concentration \\
\hline Xylitol & 20.00 \\
Glucose & 3.00 \\
Low methoxyl pectin & 0.60 \\
Vanilla $_{\mathrm{CaCl}_{2}}$ & 0.05 \\
\hline
\end{tabular}

${ }^{a}$ Different levels of xanthan gum and steviosides were also added depended on the formulation evaluated.

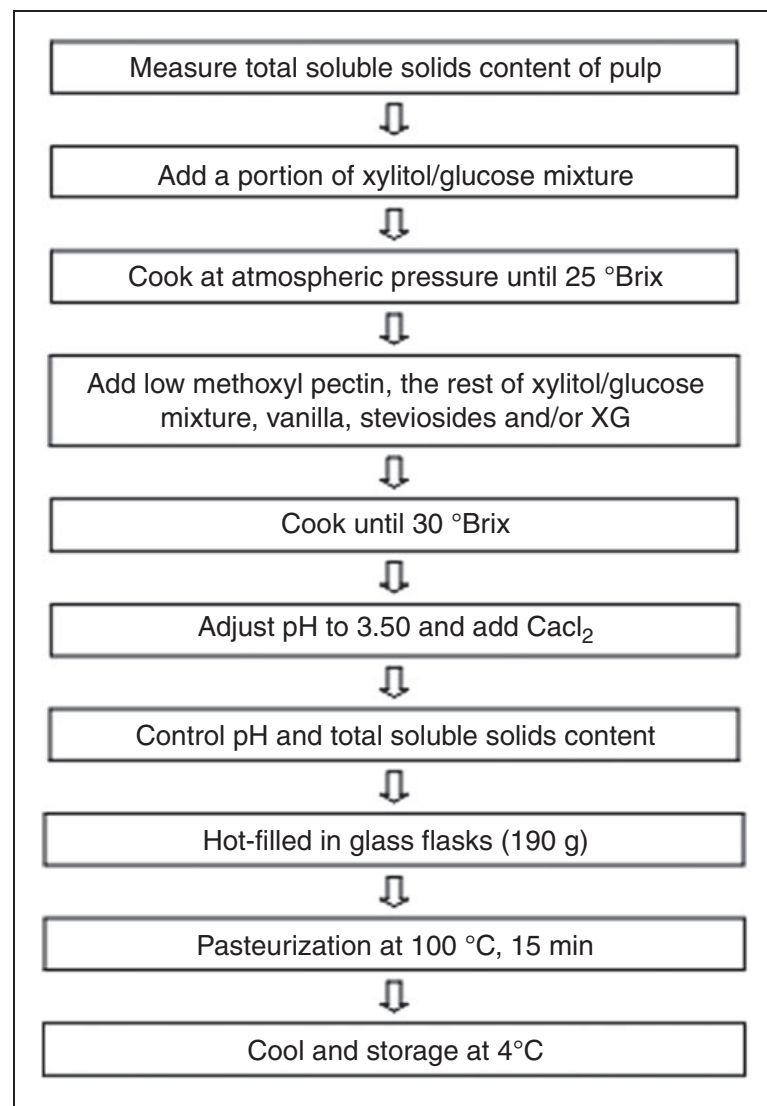

Figure 1. General processing steps in the jam production. 
$25.0 \pm 0.5^{\circ} \mathrm{C}$, the diameter of inhibition zones including the disks was measured with a caliper.

\section{Determination of minimum inhibitory concentrations of essential oils}

The tube dilution method was assayed in triplicate (O'Bryan et al., 2008). CO and CLO solutions, prepared in SB containing $0.15 \mathrm{~g} / 100 \mathrm{~g}$ bacteriological agar, with the $\mathrm{pH}$ adjusted to 3.50 by citric acid addition, were tested in the range from 0.0014 to $0.1812 \mathrm{~g} /$ $100 \mathrm{~g}$. Negative and positive controls were tested in parallel, being the former no inoculated SB, and the latter inoculated SB free of antimicrobials. Each tube, containing $3.5 \mathrm{ml}$ of system, was inoculated with $50 \mu \mathrm{L}$ of the diluted inoculums. The tubes were incubated at $25.0 \pm 0.5^{\circ} \mathrm{C}$ for five days. Then, the minimum inhibitory concentrations (MICs) were obtained as the lowest concentration at which no turn color of the indicator 2,3,5-triphenyltetrazolium chloride was observed after incubation, i.e. microbial growth inhibition compared with positive and negative controls (National Committee for Clinical Laboratory Standards, 1999).

\section{Evaluation of essential oils interactions}

The macro dilution checkerboard method was used in triplicate and the fractional inhibitory concentration indices (FIC) were calculated. The technique proposed by Tserennadmid et al. (2011) was used with some modifications. CO and CLO solutions, the range of concentrations studied ( 8 at $1 / 8$ of the MIC values), and the controls were the same as those used in the determination of MICs. Serial two-fold dilutions of each antimicrobial solution were mixed in a matrix of $10 \mathrm{ml}$ sterile tubes so that each row or column contained a fixed amount of the first antimicrobial and increasing amounts of the second one. Each matrix also contained a row and a column in which each antimicrobial was present alone (Singh et al., 2000). Each tube, containing $3.5 \mathrm{ml}$ of system, was inoculated with $50 \mu \mathrm{L}$ of the diluted inoculum. The tubes were incubated at $25.0 \pm 0.5^{\circ} \mathrm{C}$ for five days and then evaluated for their microbial growth.

The MIC of each antimicrobial, alone $\left(M I C_{A}\right.$ or $\left.M I C_{B}\right)$ and in combination $\left(M I C_{A-B}\right.$ or $\left.M I C_{B-A}\right)$, was used to calculate the FIC index as follow

$$
F I C=\frac{M I C_{A-B}}{M I C_{A}}+\frac{M I C_{B-A}}{M I C_{B}} .
$$

The type of interaction between the antimicrobials can be determined considering the FIC index value. An FIC index value near to 1 indicates addition; if it is less than 1, synergy; and if it is greater than 1, antagonism (Lopez Malo Vigil et al., 2005).

\section{Evaluation of essential oils activity in the tomato jam}

A tomato jam was elaborated (Figure 1) with the composition given in Table 2 and the addition of $0.250 \mathrm{~g} /$ $100 \mathrm{~g}$ steviosides and $0.450 \mathrm{~g} / 100 \mathrm{~g}$ XG. The jam was fractionated in glass flasks $(190 \mathrm{~g})$ to which were added, in triplicate, the MICs values of CO (0.0112 and $0.0028 \mathrm{~g} / 100 \mathrm{~g}$ for $Z$. bailii and $Z$. rouxii, respectively), the MIC of CLO $(0.0453 \mathrm{~g} / 100 \mathrm{~g}$ for both yeasts), $0.0400 \mathrm{~g} / 100 \mathrm{~g} \mathrm{CO}$ and the mixture $0.0400 \mathrm{~g} /$ $100 \mathrm{~g} \mathrm{CO}$ with the MIC of CLO. A control system free of oils was prepared for comparison purposes. After pasteurization and cooling, jams were inoculated with $Z$. bailii and $Z$. rouxii separately to a level of $10^{3} \mathrm{CFU} / \mathrm{g}$. The flasks were stored at $15.0 \pm 0.5^{\circ} \mathrm{C}$ simulating a post-process contamination and storage under inadequate refrigeration. Throughout the storage, jam samples $(5 \mathrm{~g})$ were aseptically taken from each flask and placed in sterile bags containing $45 \mathrm{ml}$ of $0.1 \mathrm{~g} / 100 \mathrm{~g}$ peptone water. Then, the viable population of yeasts was determined by surface plate count on SA after five days of incubation at $25.0 \pm 0.5^{\circ} \mathrm{C}$.

\section{Effect of CO on overall acceptability of the tomato jam}

The tomato jam containing $0.250 \mathrm{~g} / 100 \mathrm{~g}$ steviosides and $0.450 \mathrm{~g} / 100 \mathrm{~g} \mathrm{XG}$ was fractionated and $\mathrm{CO}$ was added obtaining the following levels: $0.0000-0.0060-0.0110-$ $0.0130-0.0400 \mathrm{~g} / 100 \mathrm{~g}$. After pasteurization and cooling, the jams were stored at $5.0 \pm 0.5^{\circ} \mathrm{C}$ until use.

The overall acceptability of the low sugar jams was evaluated by a group of 100 consumers ( 35 males and 65 females) of low sugar jams. The procedure and conditions were similar to the used in the previous test. This assay allowed the selection of two sensory acceptable oil levels, which were evaluated microbiologically as described in the next section.

\section{Effect of CO on microbiological stability of the tomato jam}

The simulation of a post-process contamination with the spoilage yeasts was assayed. Jam samples free of $\mathrm{CO}$ and containing 0.0060 and $0.0110 \mathrm{~g} / 100 \mathrm{~g} \mathrm{CO}$ were inoculated with $Z$. bailii and $Z$. rouxii separately reaching a level of $10^{3} \mathrm{CFU} / \mathrm{g}$. The samples were stored at $5.0 \pm 0.5^{\circ} \mathrm{C}$ and the viable population of yeasts was determined at 0,7 and 20 days of storage.

Moreover, the level of indigenous flora was determined to control the microbiological stability. 
The jams were exposed uncovered for $30 \mathrm{~min}$ at laboratory bench, stirred, closed and stored at $5.0 \pm 0.5^{\circ} \mathrm{C}$. Then, aerobic mesophilic, lactic acid, and coliform bacteria were investigated in PCA, MRS agar, and VRBL agar, respectively. The plates were incubated at $30.0 \pm 0.5^{\circ} \mathrm{C}$ for $48 \mathrm{~h}$. The yeasts and molds were determined by surface plate count on SA after five days of incubation at $25.0 \pm 0.5^{\circ} \mathrm{C}$.

\section{CO chemical analysis}

Quantitative and qualitative analysis of the most effective oil (CO) were performed by GC-FID-MS using a Perkin Elmer Clarus 500 GC-FID-MS system with a special configuration, equipped with a single split-splitless injector connected by a flow splitter to two capillary columns: a polyethylene glycol MW $c a .20 .000$ column and a 5\% phenyl-95\%-methyl silicone column, both $60 \mathrm{~m} \times 0.25 \mathrm{~mm}$ with $25 \mu \mathrm{m}$ of fixed phase (J\&W Scientific). The methodology proposed by Gil et al. (2007) was used.

\section{Cell surface hydrophobicity}

In order to check the possible effect of $\mathrm{CO}$ on cell surface, cell surface hydrophobicity was determined using the Microbial Adhesion to Hydrocarbon Test ( $\mathrm{Li}$ and McLandsborough, 1999; Rosenberg and Gutnick, 1980). The methodology proposed by Gliemmo et al. (2013) was used. Briefly, aliquots of systems containing one-half of the MIC values of $\mathrm{CO}$ were inoculated with $Z$. bailii and $Z$. rouxii, separately and they were incubated at $25.0 \pm 0.5^{\circ} \mathrm{C}$ for $24 \mathrm{~h}$ in order to obtain $\log$ phase cells. After that, the systems were centrifugated $(10,000 \mathrm{rpm}$ for $10 \mathrm{~min})$. Pellets were washed twice and resuspended in Ringer's solution at $\mathrm{pH} 3.50$, reaching a turbidity greater than the $0.5 \mathrm{Mc}$ Farland standard. Four milliliter aliquots were dispensed into two tubes. One milliliter of xylene was added to one of them $(\mathrm{Am})$, while the other was used as control $(A c)$. After 10 min of incubation, tubes were vortexed for $1 \mathrm{~min}$, and kept at room temperature for $30 \mathrm{~min}$ for phase separation. Then, $2.00 \mathrm{ml}$ of the aqueous phase was removed and the optical density $(600 \mathrm{~nm})$ was determined using a spectrophotometer (Shimadzu UV-1203, Japan), which was zeroed using Ringer's solution at $\mathrm{pH}$ 3.50. The determinations were made in triplicate. The absorbance of the microbial assay tubes $(\mathrm{Am})$ and the absorbance of the control $(A c)$ were used to calculate the percentage of cell surface hydrophobicity of yeasts as

$$
\%=\frac{A c-A m}{A c} 100 .
$$

\section{Data analysis}

Experimental data obtained from the full factorial design were subjected to a multiple regression analysis to fit the following first-order regression model

$$
Y=\alpha_{0}+\alpha_{1} x_{1}+\alpha_{2} x_{2}+\alpha_{3} x_{1} x_{2}+\varepsilon
$$

where $Y$ is the average score of overall acceptability; $\alpha_{0,1,2,3}$ are the regression coefficients for the intercept, linear, and interaction coefficients, respectively; $x_{1,2}$ are the independent variables $\left(x_{1}\right.$, level of steviosides and $x_{2}$, level of $\mathrm{XG}$ ), and $\varepsilon$ is the error term.

The adequacy of the regression model generated by the factorial design was examined by analysis of variance (ANOVA) at 5\% significance level, adjusted correlation coefficients $\left(\mathrm{R}^{2}\right)$, and the absolute average deviation (AAD) (Baş and Boyaci, 2007). Also, ANOVA and $p$-value were used to evaluate the significance of the linear and interaction terms of each model.

Analysis of variance and the Least Significant Difference (LSD) test were applied to establish differences between diameters of inhibition halos, overall acceptability scores, and cell surface hydrophobicity values.

In all cases, statistical significance was evaluated at a $5 \%$ level $(\alpha=0.05)$ and the analyses were performed using Statgraphics Plus for Windows, version 5.1 (Manugistics, Inc., Rockville, MD, USA).

\section{RESULTS AND DISCUSSION}

The water activity of jams was $0.952 \pm 0.002$, the $\mathrm{pH}$ value was $3.50 \pm 0.02$, and the total soluble solid content was $29.5 \pm 0.5^{\circ}$ Brix. These values were kept constant along 35 days of storage under refrigeration conditions.

The energetic value of jams was $17.6 \mathrm{kcal}$ per $20 \mathrm{~g}$ serving. This value represents the $33 \%$ of the caloric value of regular jams.

\section{Effect of xanthan gum and steviosides on overall acceptability of a tomato jam}

The first-order regression model for average scores of overall acceptability was fitted using the experimental data. The regression equation was

$$
\begin{aligned}
\text { Overallacceptability } & =4.48+1.26(X G) \\
& +1.33(\text { Steviosides }) \\
& +7.70(X G)(\text { Steviosides })
\end{aligned}
$$

where $(X G)$ and (steviosides) are the levels of these additives expressed in $\mathrm{g} / 100 \mathrm{~g}$. 
The adj $R^{2}$ was 0.94 , AAD was 3.63 , and $p$-values were lower than 0.002 for $\mathrm{XG}$, steviosides, and the interaction coefficients. The adj $R^{2}$ and the AAD values obtained indicate a good correlation between the observed and the predicted values of responses and that the model gives a reasonably good estimation of responses in the studied range.

In the absence of steviosides, the presence of $\mathrm{XG}$ increased overall acceptability of jams (Figure 2). The addition of steviosides to a system free of $\mathrm{XG}$ increased the overall acceptability (Figure 2).

The joint presence of XG and steviosides significantly increased overall acceptability $(p=0.002)$. This trend is shown in Figure 2 where the addition of XG to the jam containing $0.250 \mathrm{~g} / 100 \mathrm{~g}$ steviosides increased the overall acceptability in one unit.

It was reported that the increase in pectin concentration decreased the taste of a mango jam (Basu and Shivrave, 2010). The acceptability of a low calorie jelly of fruits increased by incrementing the level of a mixture of sweeteners (aspartame/acesulfame $\mathrm{K} /$ sorbitol) or the concentration of low methoxyl pectin (Acosta et al., 2008).

Levels of XG and steviosides showing appropriate values of overall acceptability will allow to compensate the decrease in sweetness, body, and mouthfeel produced by the reduction of sugar content in jams. Thus, the jam containing $0.250 \mathrm{~g} / 100 \mathrm{~g}$ steviosides and $0.450 \mathrm{~g} / 100 \mathrm{~g} \mathrm{XG}$ showed the highest score of overall acceptability (6.2).

\section{In vitro antimicrobial activity of essential oils}

Both antimicrobials showed inhibitory action on the growth of yeasts being the $\mathrm{CO}$ more effective than the CLO (Table 3). The MIC values of essential oils depended on the antimicrobials that were tested and the yeast target (Table 3). CO was the most effective in inhibiting growth, since it showed the smallest MIC values. Furthermore, both yeasts showed equal sensitivity to CLO, but $Z$. bailii was more resistant to $\mathrm{CO}$ than $Z$. rouxii. Probably, $Z$. bailii would be more resistant than $Z$. rouxii to preservatives' action as it was also reported at acidic $\mathrm{pH}$ values for lipophilic preservatives (Praphailong and Fleet, 1997).

$\mathrm{CO}$ and CLO are effective in inhibiting the growth of yeasts and bacteria. Levels of $\mathrm{CO}$ and CLO ranging from 0.0100 to $0.0200 \mathrm{~g} / 100 \mathrm{~g}$ diminished the growth of some food spoilage yeasts (Conner and Beuchat, 1984). In general, the inhibitory action of $\mathrm{CO}$ against bacteria is greater than CLO but there is no information about yeasts (Goñi et al., 2009; Prabuseenivasan et al., 2006). The sensitivity to the action of essential oils may be different among genera of yeasts and between yeasts and bacteria (Conner and Beuchat, 1984).

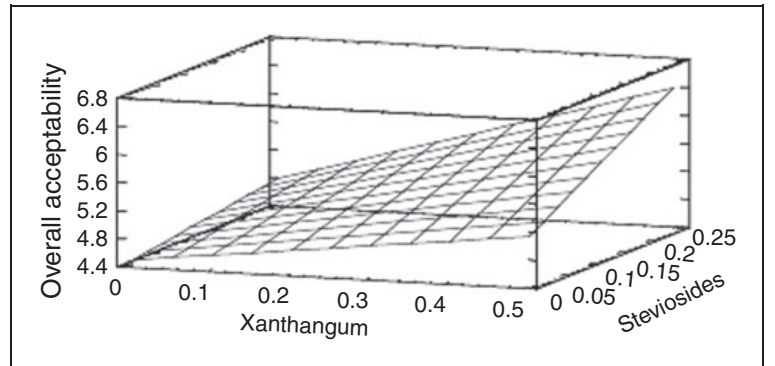

Figure 2. Estimated response surface graph for the combined effect of steviosides and xanthan gum (XG) levels on overall acceptability of jams.

Table 3. Diameters of growth inhibition halos $(\mathrm{mm})$ and minimum inhibitory concentrations (MIC) $(\mathrm{g} / 100 \mathrm{~g})$ of cinnamon (CO) and clove oils (CLO).

\begin{tabular}{lllllll}
\hline & \multicolumn{2}{c}{$\begin{array}{c}\text { Diameter } \\
\text { of halo }\end{array}$} & & \multicolumn{2}{c}{ MIC } \\
\cline { 2 - 3 } \cline { 5 - 6 } Essential oil & Z. bailii & Z. rouxii & & Z. bailii & Z. rouxii \\
\hline CO & $53.0 \pm 0.5^{\mathrm{a}}$ & $55.0 \pm 0.7^{\mathrm{a}}$ & & 0.0112 & 0.0028 \\
CLO & $23.5 \pm 0.7^{\mathrm{b}}$ & $20.0 \pm 0.8^{\mathrm{b}}$ & & 0.0453 & 0.0453 \\
\hline
\end{tabular}

${ }^{a}$ Errors represent standard deviation.

Values followed by the same letter are not significantly different $(\alpha=0.05)$.

The combined use of essential oils showed interactions that depended on yeast target and level of antimicrobials. A synergistic effect was observed on $Z$. bailii growth $\left(\mathrm{FIC}_{\mathrm{I}}=0.75\right)$ by the joint presence of $0.0028 \mathrm{~g} / 100 \mathrm{~g}$ CO together with $0.0227 \mathrm{~g} / 100 \mathrm{~g}$ CLO and $0.0056 \mathrm{~g} / 100 \mathrm{~g}$ CO together with $0.0113 \mathrm{~g} / 100 \mathrm{~g}$ CLO. Regarding the action on $Z$. rouxii, an additive effect was observed $\left(\mathrm{FIC}_{\mathrm{I}}=1.00\right)$. No information is available about the effect of combined use of $\mathrm{CO}$ and CLO on yeast growth in aqueous media. However, few studies in vapor phase indicate that the interactions depend on essential oil concentration and the target microorganism (Goñi et al., 2009; Matan et al., 2006).

\section{Antimicrobial activity of essential oils in a tomato jam}

Initially, the growth of yeasts was not modified by the presence of oils. The concentration equal to the MICs in broth slightly decreased yeast populations during storage (Figure 3). As it was observed, $\mathrm{CO}$ was more effective than CLO in the inhibition of yeasts' growth in broth, showing the lowest inhibitory levels. Then, it was decided to assay a higher level of CO $(0.0400 \mathrm{~g} / 100 \mathrm{~g})$ in the jam and its combination with the MIC of CLO.

The presence of $0.0400 \mathrm{~g} / 100 \mathrm{~g}$ CO concentration significantly diminished the growth of both yeasts. 


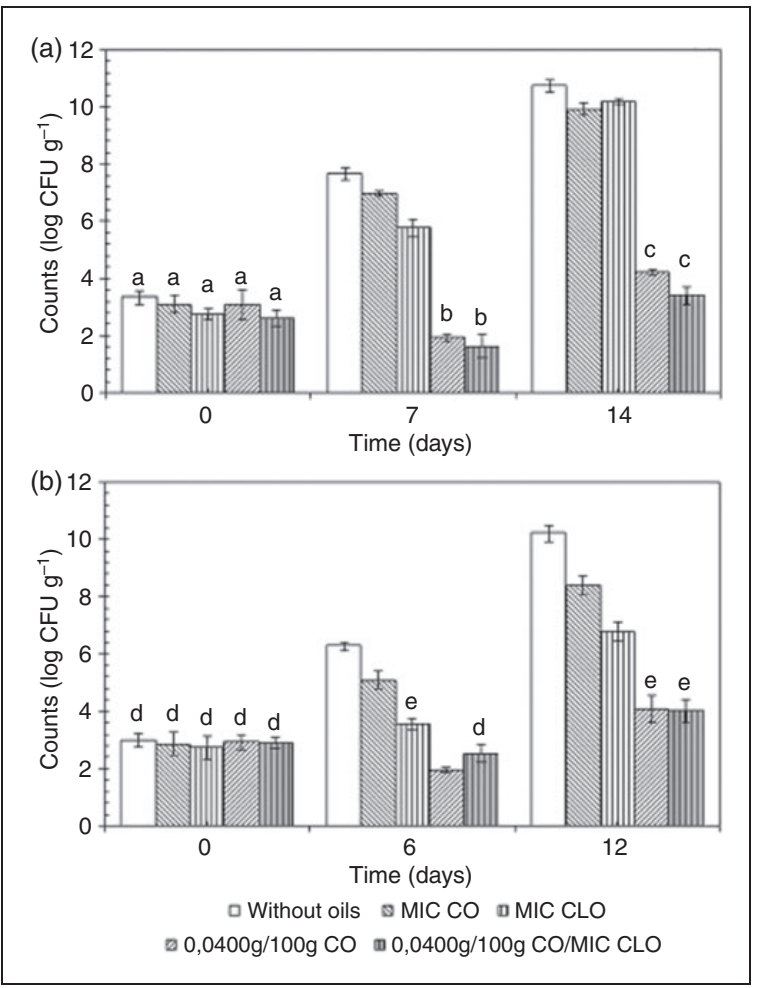

Figure 3. Effect of cinnamon oil, clove oil, and their mixture on yeast populations in the tomato jam stored at $15^{\circ} \mathrm{C}$. Z. rouxii (a), Z. bailii (b). Columns with the same letter are not significantly different $(\alpha=0.05)$. Columns without letters are significantly different $(\alpha=0.05)$. MIC: minimum inhibitory concentration.

The population of $Z$. rouxii decreased in $6 \log$ cycles after 7 and 14 days of storage (Figure 3a) whereas $Z$. bailii decreased in 4 and $6 \log$ cycles after 6 and 12 days of storage, respectively (Figure 3b).

Reductions in yeasts population observed in the jam containing $0.0400 \mathrm{~g} / 100 \mathrm{~g}$ CO and the MIC of CLO were similar to those observed in the presence of $0.0400 \mathrm{~g} / 100 \mathrm{~g} \mathrm{CO}$, indicating the absence of interaction between the oils. These results highlight the environmental influence on the oils antimicrobial activity. On one hand, the levels of essential oils with inhibitory action in laboratory media did not achieve the same effect in the jam. This is in agreement with previous studies (Lv et al., 2011; Tserennadmid et al., 2011). On the other hand, the interaction effects observed in broth were not observed in the jam. The structure of food matrix may act as an additional factor that influences either the growth of the microorganisms or the functionality of the preservatives. Cloudy apple juice protected Saccharomyces cerevisiae against the effect of lemon essential oil, while in clear apple juice it had an inhibitory action (Tserennadmid et al., 2011). Yeast cells may adhere to juice particles reducing the action of lemon oil. The nisin effectiveness against Lactobacillus fructivorans was disturbed by the presence of Tween 20 and oil in model salad dressings (Castro et al., 2009).

Since no interaction was observed between CLO and $\mathrm{CO}$ on yeasts inhibition in jam and being CLO less effective than $\mathrm{CO}$, the following assays were conducted with the latter.

\section{Effect of CO on overall acceptability of the tomato jam}

Overall acceptability of jams containing the $\mathrm{CO}$ level that exerted antimicrobial activity $(0.0400 \mathrm{~g} / 100 \mathrm{~g})$ and levels of CO close to MIC values were evaluated. The lower concentrations assayed were selected because $0.0400 \mathrm{~g} / 100 \mathrm{~g}$ may produce undesirable impact on the acceptability of the jam. After that, a few levels of $\mathrm{CO}$ were selected and the microbial stability of the jams was assayed.

The overall acceptability of jams containing different levels of $\mathrm{CO}$ is shown in Table 4. The scores were significantly different $(p=0.0154)$. Considering that the midpoint of the scale ("I do not like nor dislike") corresponds to a score of 4.5 , those jams with overall acceptability values above 5.0 were considered as "acceptable". Therefore, all jams were acceptable with the exception of the jams containing 0.0400 and $0.0130 \mathrm{~g} / 100 \mathrm{~g}$ CO. No significant differences were observed among the jams free of $\mathrm{CO}$ and the one containing $0.0110 \mathrm{~g} / 100 \mathrm{~g}$ oil. The formulation containing $0.0060 \mathrm{~g} / 100 \mathrm{~g}$ CO had the highest score and it was significantly different from the rest of the jams.

Sensory acceptable formulations $(0.0000-0.0060-$ $0.0110 \mathrm{~g} / 100 \mathrm{~g} \mathrm{CO}$ ) were submitted to microbiological evaluation.

\section{Effect of CO on microbiological stability of the tomato jam}

In the absence of $\mathrm{CO}$, counts of $Z$. rouxii and $Z$. bailii remained constant throughout the storage (Table 4). The addition of $0.0060 \mathrm{~g} / 100 \mathrm{~g}$ CO decreased yeasts' growth at 20 storage days. In jams containing $0.0110 \mathrm{~g} / 100 \mathrm{~g} \mathrm{CO}$, the growth of $Z$. rouxii diminished at 20 days while $Z$. bailii growth decreased at seven storage days (Table 4).

The counts of indigenous flora were lower than 9 $\mathrm{CFU} / \mathrm{g}$ in the selected formulations and they remained at that level after 35 days of storage.

The hurdles applied in the formulation of the jams were the decrease in $\mathrm{pH}$ through citric acid addition, $\mathrm{a}_{\mathrm{w}}$ depression by the presence of glucose and xylitol, $\mathrm{CO}$ addition, the thermal treatment, and the storage at $5^{\circ}$ C. These factors were suitable as indigenous flora did not grow during storage, indicating that the jams were elaborated in safe conditions. It is noteworthy that, 
Table 4. Overall acceptability and yeasts growth $(\mathrm{CFU} / \mathrm{g})$ in tomato jam containing different levels of cinnamon oil $(\mathrm{g} /$ $100 \mathrm{~g})$

\begin{tabular}{|c|c|c|c|c|c|c|c|}
\hline \multirow[b]{3}{*}{ CO level } & \multirow[b]{3}{*}{ Overall acceptability } & \multicolumn{6}{|c|}{ Yeast growth at different storage time (days) } \\
\hline & & \multicolumn{3}{|c|}{ Z. rouxii } & \multicolumn{3}{|c|}{ Z. bailii } \\
\hline & & 0 & 7 & 20 & 0 & 7 & 20 \\
\hline 0.0000 & $5.0^{\mathrm{a}}$ & $8.7 \times 10^{2}$ & $7.2 \times 10^{2}$ & $6.3 \times 10^{2}$ & $9.8 \times 10^{2}$ & $6.0 \times 10^{2}$ & $6.9 \times 10^{2}$ \\
\hline 0.0060 & 6.2 & $9.0 \times 10^{2}$ & $6.1 \times 10^{2}$ & $<9.0 \times 10^{1}$ & $8.4 \times 10^{2}$ & $3.1 \times 10^{2}$ & $9.0 \times 10^{1}$ \\
\hline 0.0110 & $4.9^{\mathrm{a}}$ & $9.0 \times 10^{2}$ & $6.3 \times 10^{2}$ & $<9.0 \times 10^{1}$ & $8.8 \times 10^{2}$ & $9.0 \times 10^{1}$ & $<9.0 \times 10^{1}$ \\
\hline 0.0130 & 4.5 & - & - & - & - & - & - \\
\hline 0.0400 & 1.3 & - & - & - & - & - & - \\
\hline
\end{tabular}

Note: Means in columns followed by the same superscripts are not significantly different $(p<0.05)$.

although in the absence of $\mathrm{CO}$ the others factors ensured the microbiological stability of the jam, CO addition may be useful in a situation of contamination with resistant yeasts to the stress factors applied. That is the case of $Z$. bailii and $Z$. rouxii (Loureiro and Querol, 1999). The essential oil levels were not high enough to cause death of microorganisms, but they were sufficient to produce the stasis of growth.

The use of steviosides, $\mathrm{XG}$ and $\mathrm{CO}$ in a low sugar tomato jam may provide a safe and sensory acceptable formulation contributing to the development of safe and healthy food.

\section{CO effectiveness related to the chemical composition and the cell surface hydrophobicity}

The chemical composition of $\mathrm{CO}$ is shown in Table 5. Fifteen compounds were identified, representing 96.8\% of the total oil. The major constituent was $(E)$ Cinnamaldehyde (78.7\%) followed by Eugenol (5.4\%).

The effectiveness of $\mathrm{CO}$ is particularly attributed to the inhibitory action of cinnamaldehyde. Its action against bacteria, yeasts, and molds has been reported. It has been suggested that the carbonyl group of cinnamaldehyde would bind to proteins affecting the action of amino acid decarboxylases in Enterobacter aerogenes (Ali et al., 2005; Burt, 2004; Matan et al., 2006). Also, the minor components may interact with major components resulting in additive or synergistic effects. The mixture of cinnamaldehyde and eugenol synergistically acted inhibiting the growth of some pathogenic bacteria (Burt, 2004).

On the other hand, $\mathrm{CO}$ addition decreased the percentage of cell surface hydrophobicity of yeasts from $91 \pm 3$ to $57 \pm 1$ for $Z$. rouxii and from $86.0 \pm 0.1$ to $44 \pm 4$ for $Z$. bailii. It was proposed that a change in the amount of cells that can adhere to a solvent is an expression of a change in surface structure (Ming and Daeschel, 1995).
Table 5. Chemical composition of cinnamon essential oil.

\begin{tabular}{lcc}
\hline Compounds & $\mathrm{g} / 100 \mathrm{~g}$ & RI no polar \\
\hline$\alpha$-Pinene & 0.9 & 945 \\
$\beta$-Pinene & 0.6 & 994 \\
$\alpha$-Phellandrene & 0.6 & 1017 \\
$\rho$-Cymene & 1.6 & 1031 \\
Limonene & 2.4 & 1034 \\
1,8-Cineole & 2.0 & 1041 \\
Linalool & 0.8 & 1107 \\
Camphor & 0.2 & 1172 \\
$\alpha$-Terpineol & 0.7 & 1211 \\
$\gamma$-Terpineol & 0.3 & 1215 \\
(Z)-Cinnamaldehyde & 0.2 & 1244 \\
Linalool acetate & 0.6 & 1252 \\
(E)-Cinnamaldehyde & 78.7 & 1303 \\
Eugenol & 5.4 & 1360 \\
$\beta$-Caryophyllene & 1.8 & 1437 \\
TOTAL & 96.8 &
\end{tabular}

Note: $\mathrm{Rl}$, retention indices relative to $\mathrm{C}_{6}-\mathrm{C}_{24} \mathrm{n}$-alkanes on the column.

The mode of antimicrobial action of essential oils is related to their interaction with the lipids of cell membrane and the mitochondria increasing its permeability, causing swelling and reducing membrane function. Also, lipophilic compounds of essential oils may interact with hydrophobic sites of proteins located in the cytoplasmic membrane (Burt, 2004; Sikkema et al., 1994). Furthermore, the effectiveness of these interactions depends on the range of hydrophobicity of essential oils since aqueous solubility is a limiting factor of the accumulation of hydrophobic compounds in the cell membrane to lethal levels (Goñi et al., 2009).

No information about the relation between the effect of $\mathrm{CO}$ or cinnamaldehyde on yeast cell membrane and changes in the hydrophobicity of cells has been found. 
In the present study, the interaction between $\mathrm{CO}$ and yeasts cell membrane may be the cause of the drop in the percentage of cell surface hydrophobicity of yeasts.

\section{CONCLUSIONS}

Levels of XG and steviosides showing appropriate values of jam overall acceptability were found. This would allow compensating the decrease in sweetness, body, and mouthfeel produced by the reduction of sugar content in the jam. The essential oils assayed showed synergistic and additive effects in vitro on growth of $Z$. bailii and $Z$. rouxii, respectively. However, in the jam, $\mathrm{CO}$ was more effective and CLO did not modify the $\mathrm{CO}$ action. Cell surface was one of the sites of action of CO. It was found a suitable level of $\mathrm{CO}$ from the microbiological and sensory points of view. Although this level did not cause yeast inactivation, it could be useful as an additional stress factor against yeast post-process contamination. The adequate levels of $\mathrm{XG}$, steviosides, and $\mathrm{CO}$ found may improve the quality of a low sugar jam formulation.

\section{DECLARATION OF CONFLICTING INTERESTS}

The authors declare that there is no conflict of interest.

\section{FUNDING}

We acknowledge the financial support from Universidad de Buenos Aires, Consejo Nacional de Investigaciones Científicas y Técnicas de la República Argentina and Agencia Nacional de Investigaciones Científicas y Tecnológicas de la República Argentina.

\section{REFERENCES}

Acosta O, Víquez F and Cubero E. (2008). Optimization of low calorie mixed fruit jelly by response surface methodology. Food Quality and Preference 19: 79-85.

Ali SM, Khan AA, Ahmed I, Musaddiq M, Ahmed KS, Polasa H, et al. (2005). Antimicrobial activities of Eugenol and Cinnamaldehyde against the human gastric pathogen Helicobacter pylori. Annals of Clinical Microbiology and Antimicrobials 4: 20.

Baş D and Boyaci IH. (2007). Modeling and optimization I: Usability of response surface methodology. Journal of Food Engineering 78: 836-845.

Basu S and Shivrave US. (2010). Rheological, textural, microstructural and sensory properties of mango jam. Journal of Food Engineering 100: 357-365.

Burt S. (2004). Essential oils: their antibacterial properties and potential applications in foods-a review. International Journal of Food Microbiology 94: 223-253.

Castro MP, Rojas AM, Campos CA and Gerschenson LN. (2009). Effect of preservatives, tween 20, oil content and emulsion structure on the survival of Lactobacillus fructivorans in model salad dressings. LWT - Food Science and Technology 42: 1428-1434.

Chatsudthipong V and Muanprasat C. (2009). Stevioside and related compounds: Therapeutic benefits beyond sweetness. Pharmacology \& Therapeutics 121: 41-54.

Conner DE and Beuchat LR. (1984). Effects of essential oils from plants on growth of food spoilage yeasts. Journal of Food Science 49: 429-434.

Deak T. (2008). Yeasts in specific types of foods. In: Deak T and Beuchat LR (eds) Handbook of Food Spoilage Yeasts. Boca Ratón: CRC Press, pp. 117-201.

Gajar AM and Badrie N. (2001). Processing and quality evaluation of a low-calorie christophene jam (Sechium edule (Jacq.) Swartz. Journal of Food Science 67: 341-346.

García-Ochoa F, Santos VE, Casas JA and Gómez E. (2000). Xanthan gum: Production, recovery, and properties. Biotechnology Advances 18: 549-579.

Gil A, Van Baren CM, Di Leo Lira PM and Bandoni BL. (2007). Identification of the genotype from contents and composition of the essential oil of Lemon verbena (Aloysia citriodora Palau). Journal of Agriculture and Food Chemistry 55: 8664-8669.

Gliemmo MF, Campos CA and Gerschenson LN. (2006). Effect of several humectants and potassium sorbate on the growth of Zygosaccharomyces bailii in model aqueous systems resembling low sugar products. Journal of Food Engineering 77: 761-770.

Gliemmo MF, Schelegueda LI, Gerschenson LN and Campos CA. (2013). Effect of aspartame and other additives on the growth and thermal inactivation of Zygosaccharomyces bailii in acidified aqueous systems. Food Research International 53: 209-217.

Goñi P, López P, Sánchez C, Gómez-Lus R, Becerril R and Nerín C. (2009). Antimicrobial activity in the vapour phase of a combination of cinnamom and clove essential oils. Food Chemistry 116: 982-989.

Gutierrez J, Rodriguez G, Barry-Ryan C and Bourke P. (2008). Efficacy of plant essential oils against foodborne pathogens and spoilage bacteria associated with ready-toeat vegetables: antimicrobial and sensory screening. Journal of Food Protection 71: 1846-1854.

Li J and McLandsborough LA. (1999). The effects of the surface charge and hydrophobicity of Escherichia coli on its adhesion to beef muscle. International Journal of Food Microbiology 53: 185-193.

Lopez Malo Vigil A, Palou E, Parish ME and Davidson PM. (2005). Methods for activity assay and evaluation of results. In: Davidson PM, Sofos JN and Branen AL (eds) Antimicrobials in Foods. Boca Ratón: CRC Press, pp. 659-680.

Loureiro V and Querol A. (1999). The prevalence and control of spoilage yeasts in foods and beverages. Trends in Food Science \& Technology 10: 356-365.

Lv F, Liang H, Yuan Q and Li C. (2011). In vitro antimicrobial effects and mechanism of action of selected plant essential oil combinations against four food-related microorganisms. Food Research International 44: 3057-3064.

Matan N, Rimkeeree H, Mawson AJ, Chompreeda P, Haruthaithanasan V and Parker M. (2006). Antimicrobial activity of cinnamon and clove oils under 
modified atmosphere conditions. International Journal of Food Microbiology 107: 180-185.

Meilgaard M, Civille GV and Carr BT. (1987). Sensory Evaluation Techniques. Boca Raton: CRC Press.

Ming X and Daeschel MA. (1995). correlation of cellular phospholipid content with nisin resistance of Listeria monocytogenes Scott A. Journal of Food Protection 58: 416-420.

Mytle N, Anderson GL, Doyle MP and Smith MA. (2006). Antimicrobial activity of clove (Syzgium aromaticum) oil in inhibiting Listeria monocytogenes on chicken frankfurters. Food Control 17: 102-107.

National Committee for Clinical Laboratory Standards (1999). Methods for Determining Bactericidal Activity of Antimicrobial Agents. Approved guideline. NCCLS document M26-A. Wayne: National Committee for Clinical Laboratory Standards.

O'Bryan CA, Crandall PG, Chalova VI and Ricke SC. (2008). Orange essential oils antimicrobial activities against Salmonella spp. Journal of Food Science 73: M26-M267.

Prabuseenivasan S, Jayakumar M and Ignacimuthu S. (2006). In vitro antibacterial activity of some plant essential oils. BMC Complementary and Alternative Medicine 6: 39. DOI: 10.1186/1472-6882-6-39.

Prakash I, DuBois GE, Clos JF, Wilkens KL and Fosdick LE. (2008). Development of rebiana, a natural, non-caloric sweetener. Food Chemistry and Toxicology 46: S75-S82.

Praphailong W and Fleet GH. (1997). The effect of $\mathrm{pH}$, sodium chloride, sucrose, sorbate and benzoate on the growth of food spoilage yeasts. Food Microbiology 14: 459-468.

Rosenberg M and Gutnick D. (1980). Adherence of bacteria to hydrocarbons: a simple method for measuring cell surface hydrophobicity. FEMS Microbiological Letters 9: 29-33.

Scott-Thomas C. (2013). Stevia approval opened new sweetener category, says Cargill. Available at: http://www.food navigator.com/Financial-Industry/Stevia-approvalopened-new-sweetener-category-says-Cargill (accessed 7 August 2014).

Sikkema J, de Bont JAM and Poolman B. (1994). Interactions of cyclic hydrocarbons with biological membranes. Journal of Biological Chemistry 269: 8022-8028.

Sikora M, Badrie N, Deisingh AK and Kowalski S. (2008). Sauces and dressings: a review of properties and applications. Critical Reviews in Food Science and Nutrition 48: 50-77.

Singh PK, Tack BF, McCray PB Jr and Welsh MJ. (2000). Synergistic and additive killing by antimicrobial factors found in human airway surface liquid. American Journal of Physiology-Lung Cellular and Molecular Physiology 279: 799-805.

Stiles BA, Duffy S and Schaffner D. (2002). Modelling yeast spoilage in cold filled ready to drink beverages with Saccharomyces cerevisiae, Zygosaccharomyces bailii and Candida lipolytica. Applied and Environmental Microbiology 68: 1901-1906.

Tserennadmid R, Takó M, Galgóczy L, Papp T, Pesti M, Vágvölgyi C, et al. (2011). Anti yeast activities of some essential oils in growth médium, fruit juices and milk. International Journal of Food Microbiology 144: 480-486.

World Health Organization. (2014). Obesity and overweight. Available at: http://www.who.int/mediacentre/factsheets/ fs311/en/index.html (accessed 7 August 2014). 